\title{
ChemComm
}

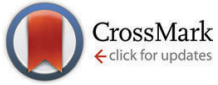

Cite this: Chem. Commun., 2015, 51,14528

Received 22nd June 2015

Accepted 7th August 2015

DOI: $10.1039 / \mathrm{c5cc05106a}$

www.rsc.org/chemcomm

\section{Reusable and specific proton transfer signalling by inorganic cyanide in solution and solid phase $\uparrow$}

\author{
Masood Ayoub Kaloo and Jeyaraman Sankar*
}

\begin{abstract}
A highly specific cyanide mediated proton transfer signalling (PTS) is exhibited by a simple diaminomalenonitrile (DAMN) derivative 1. By virtue of the functional groups on it, the chromophore offered a rigid anchoring on a silica surface via a simple dip method, while retaining the recognition behaviour. The PTS triggered a prompt dualmodal display i.e., chromogenic and fluorogenic. The signal readout can be visualized even in micromolar concentrations. It is noteworthy that PTS can be reversed in both solution and solid phases. The remarkable sensitivity of 1 to detect $\mathrm{CN}^{-}$from the solution and solid phase envisages a pivotal step towards field-usable sensing.
\end{abstract}

Innovative receptor approaches for transforming recognition properties into suitable and practical applications for environmental, biological and chemical processes is an area of considerable interest and challenge. ${ }^{1}$ An ideal choice will be to model a molecule possessing remarkable selectivity and sensitivity for toxic analytes dissolved in aqueous media. Among the various hazardous analytes, cyanide exists as one of the crucial anionic species. ${ }^{2}$ Due to its applications in the fibre, resin, and herbicide industry and leaching extraction of gold from the ore and electroplating, its monitoring becomes significant once released into the environment. ${ }^{3}$ Owing to this widespread use in innumerable processes and acute toxicity, detection and estimation of cyanide in the environment becomes very important. Since it does not decompose easily, very minute amounts are also highly detrimental and a potential threat to both flora and fauna. ${ }^{4-6}$ Molecular receptor approaches can overcome the bulky and sophisticated instrumentation, tedious and sample preconcentration, delayed signal readout and high detection limits, associated with the existing methods. ${ }^{7-12}$ Thus, receptors offering selective and

Department of chemistry and Centre for Research on Environmental and Sustainable Technologies, [established under MHRD - Fast scheme], Indian Institute of Science Education and Research Bhopal, Bhauri, Indore-bypass, Bhopal, 462066, India. E-mail: sankar@iiserb.ac.in; Fax: +91-755-6692392; Tel: +91-755-6692334 $\dagger$ Electronic supplementary information (ESI) available: ${ }^{1} \mathrm{HMR},{ }^{13} \mathrm{C}$, Job's plot, binding constant calculations, absorption and emission spectra and calibration plots. CCDC 957578. For ESI and crystallographic data in CIF or other electronic format see DOI: 10.1039/c5cc05106a sensitive recognition for inorganic cyanide (IC) will be a step towards practical applications, rather than unrealistic tetra butyl ammonium (TBA) based cyanide. ${ }^{13,14}$ This is challenging due to the high solvation energy of $\mathrm{CN}^{-}$in aqueous solutions. ${ }^{15}$ Alternatively, $\mathrm{CN}^{-}$recognition as IC has been achieved through chemical reaction based chemodosimetric and/or coordination approaches. ${ }^{16}$ Many functional materials with rhodamine, coumarin, BODIPY, hemicyanine, calixpyrrole, oxazine, naphthalimide, hemicyanine, azo zincon and benzofuran based units have been reported. ${ }^{17}$ In addition, their hybrids, ensembles and metal complexes have also been proposed. ${ }^{18}$ Even though selectivity has been achieved to some extent via such approaches, obstacles like irreversibility, delayed signal output, tedious molecular fabrication requirements and high detection limits still remain. Hence, a novel receptor platform for highly sensitive $\mathrm{CN}^{-}$recognition via reusable and easy to fabricate design is necessary.

In addition to the solution phase, a heterogeneous strategy for quick and on-site $\mathrm{CN}^{-}$sensing outside the laboratory applications has been attempted using films, membranes, supported surfaces, etc. ${ }^{19}$ The adsorption of receptors to solid supports offers portability, simple operation protocol and reusability. However, existing approaches for solid phase $\mathrm{CN}^{-}$ sensing utilize complex molecules and hence involve a tedious synthetic protocol. Further, all these approaches are purely chemical reaction based and thus yield a weak signal transduction with a delayed response. Thus there is a need to develop a new receptor protocol for $\mathrm{CN}^{-}$recognition, with the ease of dip-sensing and reusability, apart from solution phase applications.

Encouraged by these challenges, along with a considerable interest in the development of new approaches for anion recognition through hydrogen-bonding or deprotonation based paradigm, we utilized the design strategies based on the strong "push and pull" properties of DAMN materials. It has been established that the photophysical properties of these chromophores are highly dependent on the electron donor/acceptor strength. ${ }^{19}$ Consequently, if the anion binding site itself is a part of a donor (D) or acceptor (A) in the ICT based receptor design, a highly effective signal communication could be 

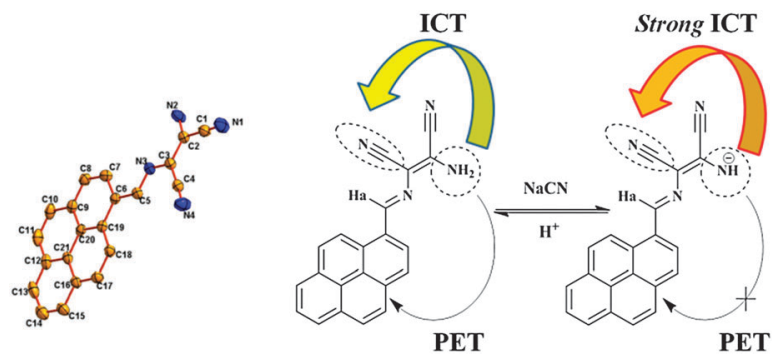

Fig. 1 (left) ORTEP representation of the crystal structure of the receptor (1) (CCDC 957578). (right) $\mathrm{NaCN}$ induced PTS promotes charge transfer (ICT) enhancement and further prevents PET quenching of fluorophore from the amine $\left(-\mathrm{NH}_{2}\right)$ moiety.

expected. We demonstrate here this approach by providing a convenient bi-phasic (solution and solid phase) recognition platform for inorganic cyanide.

While exploring the DAMN receptor approach for the sensing of sodium or potassium salt based anions, we obtained a highly robust and extensively conjugated, 2-amino-( (E)-(pyren-1-ylmethylene) amino) maleonitrile (1, Fig. 1) exhibiting ICT and photoinduced electron transfer (PET) properties..$^{20} 1$ was obtained according to a reported methodology utilizing reflux conditions (12 hours) and finally purified by column chromatography. ${ }^{21}$ It was noticed that the compound was tailing in the column and eluted via partial decomposition. This led us to the search for an efficient synthetic protocol. A simple method was devised by dissolving pyrene-1-carbaldehyde in an ethanol/water mixture $(8: 2, \mathrm{v} / \mathrm{v})$, added with a trace amount of concentrated acid $(\mathrm{HCl})$. This was followed by a drop-wise addition of amine (DAMN). The addition proceeded with the immediate precipitation of the Schiff base product (within a minute). The precipitate was filtered, washed and recrystallized using ethanol and characterised by mass spectrometry, NMR $\left({ }^{1} \mathrm{H}\right.$ NMR, ${ }^{13} \mathrm{C}$ NMR in S2, ESI $\left.\dagger\right)$ and single-crystal XRD (Fig. 1). It is important to mention that our methodology was not only simple but also ended up with an improved yield, of up to $95 \%$.

The adhesive nature of $\mathbf{1}$ towards silica was exploited to develop a solid-support material by simple dipping of thin layer silica gel plates (TLC) into the solution of $\mathbf{1}$, followed by drying in ambient air. It was surprising to see an extremely stable nature of this film even after immediately washing with water several times (Fig. 2). This offers a clear advantage over the existing approaches that utilize supports like $\mathrm{TiO}_{2}$, zeolites, $\mathrm{Al}_{2} \mathrm{O}_{3}$, etc. ${ }^{22}$ The strong binding nature of $\mathbf{1}$ to the silica plate can be probably realized in terms of a characteristic DAMN moiety associated with it.

The recognition behaviour of $\mathbf{1}$ was evaluated in a mixed solvent system around a neutral $\mathrm{pH}$ range (6.7-7.4) with DMSO/HEPES $(8: 2, \mathrm{v} / \mathrm{v})$. This was followed by addition of aqueous solutions of sodium or potassium salts of various common anions $\left(\mathrm{F}^{-}, \mathrm{Cl}^{-}, \mathrm{Br}^{-}\right.$, $\mathrm{I}^{-}, \mathrm{CN}^{-}, \mathrm{HSO}_{4}^{-}, \mathrm{SO}_{4}{ }^{-2}, \mathrm{NO}_{3}^{-}, \mathrm{HPO}_{4}{ }^{-2}, \mathrm{H}_{2} \mathrm{PO}_{4}^{-}, \mathrm{HCO}_{3}^{-}$and $\mathrm{CH}_{3} \mathrm{COO}^{-}$). Strong colorimetric and fluorescence changes were observed through the naked eye selectively with $\mathrm{CN}^{-}$addition (Fig. 3). Among other anions, $\mathrm{HPO}_{4}{ }^{-2}$ and $\mathrm{HCO}_{3}{ }^{-}$came up with a very weak visual response, after addition of 100 -fold concentration

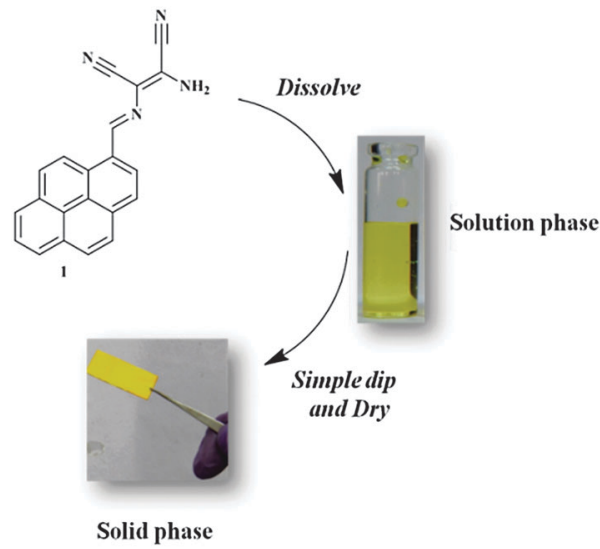

Fig. 2 A simple dip based preparation of the highly robust DAMN-receptor film on the TLC plate.
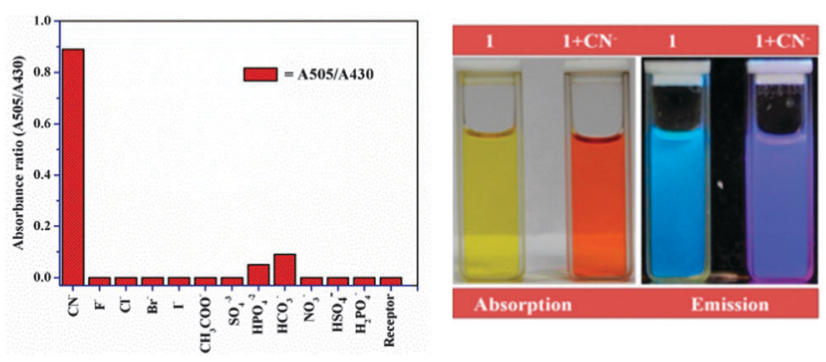

Fig. 3 (left) Bar graph presenting high selectivity of 1 for $\mathrm{CN}^{-}$. Observations were made by addition of 7.0 equivalents of sodium cyanide ( $\mathrm{NaCN}, 0.3 \mathrm{mM}$ ) in water to $1\left(20.6 \times 10^{6} \mathrm{M}\right)$ in DMSO. Other anions were used in 100 -fold concentrations. (right) Visual display of $\mathrm{CN}^{-}$mediated PTS in absorption and emission mode.

to that of $\mathrm{CN}^{-}$, while others stayed neutral with respect to these changes. The observations were further investigated through various spectroscopic techniques.

The UV-Vis spectra of free receptor 1 in DMSO/HEPES $(8: 2, \mathrm{v} / \mathrm{v})$ medium displays a characteristic absorption band centred at $430 \mathrm{~nm}$ along with a weak absorption signal at $345 \mathrm{~nm}$. The absorption band at $430 \mathrm{~nm}$ is associated with two shoulder bands on either sides at $400 \mathrm{~nm}$ and $450 \mathrm{~nm}$. In the presence of $\mathrm{CN}^{-}, 1$ results in an immediate red-shift of the $430 \mathrm{~nm}$ signal. The absorption at $430 \mathrm{~nm}$ gradually subsides with a concomitant increase of new bands at $505 \mathrm{~nm}$ and $345 \mathrm{~nm}$ (Fig. 4a). These changes are associated with two simultaneous isosbestic points at $468 \mathrm{~nm}$ and $367 \mathrm{~nm}$, signifying two different species in equilibrium. The given changes are attributed to the enhancement of the ICT transition from a donor to an acceptor. The CT enhancement is an outcome of the increase in the negative charge density on amine nitrogen at the receptor site. The modulation is proposed to occur either by hydrogen-bonding or intermolecular proton transfer from $\mathbf{1}$ to $\mathrm{CN}^{-}$. This can be well understood in terms of the strong polar nature of the $-\mathrm{N}-\mathrm{H}$ bond, attributed to the electron withdrawing environment of $\mathrm{CN}$ groups.

The selectivity of $\mathbf{1}$ for $\mathrm{CN}^{-}$is attributed to its weak hydration enthalpy $\left(-295 \mathrm{~kJ} \mathrm{~mol}^{-1}\right)$ and strong basicity. ${ }^{23}$ These characteristics allow $\mathrm{NaCN}$ to interact with the polarised $-\mathrm{N}-\mathrm{H}$ bond of the receptor 


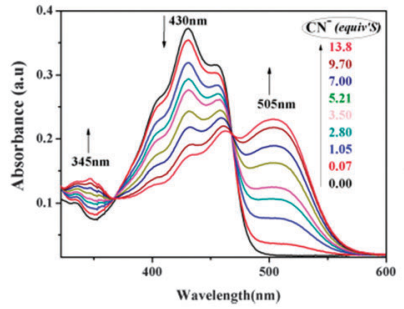

(a)

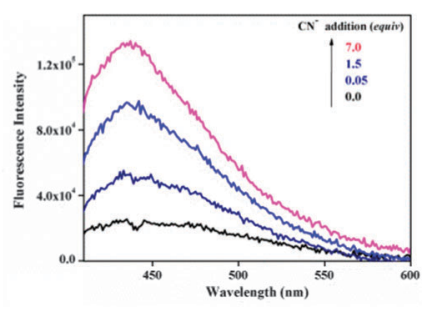

(b)
Fig. 4 (a), UV/Vis titration profile of $1\left(20.6 \times 10^{-6} \mathrm{M}\right)$ upon addition of $\mathrm{NaCN}(0.3 \mathrm{mM})$ in DMSO/HEPES $(8: 2, \mathrm{v} / \mathrm{v})$. (b) Emission response of 1 $\left(7.5 \times 10^{-6} \mathrm{M}\right)$ with $\mathrm{NaCN}$ in DMSO/HEPES $(8: 2, \mathrm{v} / \mathrm{v})$ upon excitation at $390 \mathrm{~nm}$. All these experiments were carried out at $298 \mathrm{~K}$.

in aqueous solution. ${ }^{24}$ On the basis of $1: 1$ stoichiometry by Job's method, the binding constant $(K)$ of $\mathbf{1}$ with $\mathrm{CN}^{-}$was calculated to be $1.35 \times 10^{4} \mathrm{M}^{-1}$ (S3 and S4, ESI $\dagger$ ).

The changes in the ground state of $\mathbf{1}$ by $\mathrm{CN}^{-}$were also manifested in the excited state, where intensity changes in the fluorescence emission spectra were readily observed through the naked eye (Fig. 3, right). Upon excitation at $390 \mathrm{~nm}, \mathbf{1}$ exhibits a low intensity (partly quenched) emission band centred at $445 \mathrm{~nm}$ (Fig. 4b). The presence of $\mathrm{CN}^{-}$results in the pyrene emission "ON" and continues with further additions. The intensity changes are probably an outcome of strong ICT enhancement from $-\mathrm{NH}_{2}$ towards the acceptor $(-\mathrm{CN})$. The strong ICT from the donor to the acceptor in turn prevents quenching of pyrene emission via PET.

In order to cross-check the proposed mechanism and spectral observations, a strong base in the form of the hydroxide anion (TBAOH) in DMSO was added to $\mathbf{1}$. Here the reproducibility of results, similar to NaCN confirmed proton transfer from $\mathbf{1}$ to $\mathrm{CN}^{-}$(S5, ESI $\dagger$ ).

The proposed mechanism of $\mathrm{CN}^{-}$interaction with the receptor was finally probed through ${ }^{1} \mathrm{H}$ NMR spectroscopy. Titration of 1 in $\mathrm{d}_{6}$-DMSO with $2 \mathrm{mM}$ TBACN in THF resulted in the disappearance of the $-\mathrm{NH}_{2}$ peak at $8.12 \mathrm{ppm}$, upon addition of less than 1 equivalent of $\mathrm{CN}^{-}$(Fig. 5). These observations confirmed a single-step PTS mechanism of $\mathrm{CN}^{-}$ and receptor interaction rather than hydrogen-bonding. The imine proton $\left(\mathrm{H}_{\mathrm{a}}\right)$ and other proton signals also resulted in an upfield or downfield shift, implicating an induced charge transfer and electron transfer across the system.

In order to utilize the observed spectral changes of 1 with $\mathrm{NaCN}$ as a potential tool for the quantification of $\mathrm{CN}^{-}$in drinking water, it was very important to deduce the limits of detection for $\mathrm{NaCN}$. This was achieved by constructing calibration plots of the absorption and emission response of the receptor in the presence of NaCN. A near-linear correlation exists for the absorption response at $550 \mathrm{~nm}\left(\mathrm{~A}_{505 \mathrm{~nm}}\right)$ and intensity changes at $445 \mathrm{~nm}$ $\left(\mathrm{I}_{445 \mathrm{~nm}}\right)$ with respect to $\mathrm{CN}^{-}$concentration (S6 and S7, ESI $\dagger$ ). In absorption mode, 1 can detect $\mathrm{CN}^{-}$up to a minimum of $7.5 \mu \mathrm{M}$. However in the emission response, a very low detection limit was achieved $(1.98 \mu \mathrm{M})$. It is notable that the calculated value is well within the permissive level for cyanide in drinking water as per World Health Organization (WHO) guidelines. ${ }^{25}$

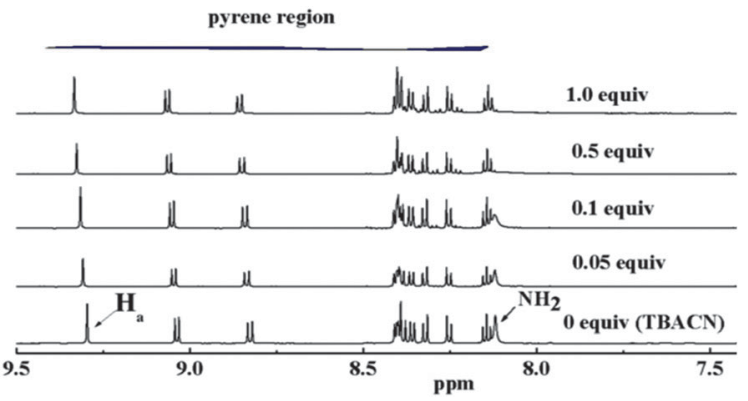

Fig. 5 Complete ${ }^{1} \mathrm{H}$ NMR of $1(25 \mathrm{mM})$ in $\mathrm{d}_{6}$-DMSO with TBACN (2 mM) in THF. The experiment was carried out at $298 \mathrm{~K}$.

During the course of our anion recognition studies, we observed a vivid colorimetric display from receptor solution in the presence of various $\mathrm{CN}^{-}$additions. We envisaged this as a probable basis for the naked eye based inorganic cyanide quantification for a range of concentrations through the chromogenic behaviour of the solution. After detailed screening of various receptor concentrations with different cyanide concentrations, a visual chromogenic display for the semi-quantitative estimation of cyanide was achieved with $0.050 \mathrm{mM}$ of 1 (Fig. 6). This presents one of the rare observations regarding receptor systems for inorganic cyanide.

In order to deduce the reusable behaviour of $\mathrm{CN}^{-}$mediated PTS, the addition of a control input in the form of the $\mathrm{H}^{+}$source $\left(\mathrm{H}_{2} \mathrm{SO}_{4}, \mathrm{HCl}, \mathrm{TFA}\right)$ was used. An immediate colorimetric change was seen. This can be understood in terms of protonation of negatively charged receptor species, further supporting the PTS. Interestingly, given behaviour was reproducible multiple times with alternate additions of $\mathrm{CN}^{-}$and $\mathrm{H}^{+}$(Fig. 7). It is clear that the initial state of the molecule (presented as black, A430 nm) is almost fully recovered up to five cycles while as the deprotonated receptor species (presented red, A505 nm)

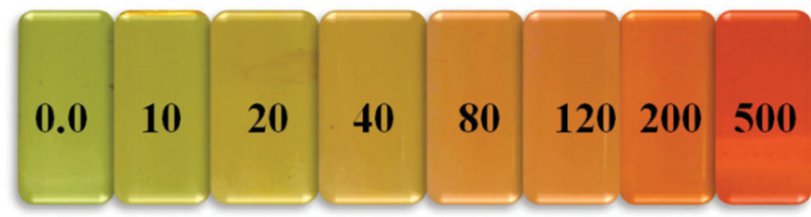

Fig. 6 Colorimetric display for various concentrations of cyanide in $\mu \mathrm{M}$. Photograph taken immediately after $\mathrm{NaCN}$ additions with $0.050 \mathrm{mM}$ of 1 under ambient conditions.

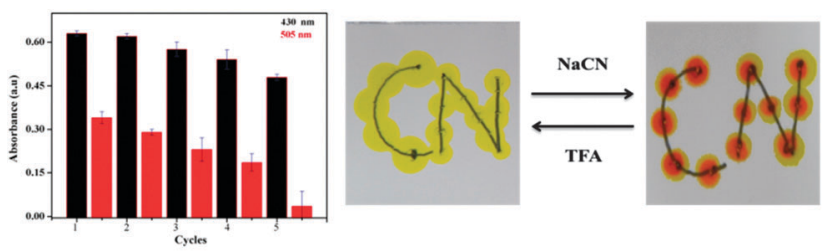

Fig. 7 (left) Recyclable nature of the receptor for cyanide with error bars. Observations with $0.028 \mathrm{mM}$ of 1 upon alternate additions of 20-40 equivalents of $\mathrm{CN}^{-}$and acid. (right) Naked eye and reusable solid phase detection of $\mathrm{NaCN} / \mathrm{KCN}$. 
loses its efficiency continuously with each recovery. Further and most importantly, the chromogenic changes were also observed in the solid phase of the receptor in the presence of NaCN/KCN. The observed chromogenic behaviour was instantaneous, similar to the solution based response. This further offered recyclability upon exposure to acid (Fig. 7), indicating operation of the PTS mechanism in the solid phase, in addition to the solution phase. This further adds to the insights of the demonstrated receptor exploration for inorganic cyanide sensing in aqueous media.

For the first time, an easy-to-prepare pyrene-DMN Schiff base has been explored and developed as a promising receptor exhibiting specific NaCN/KCN recognition in both solution and solid phases. The interaction triggers instantaneous chromogenic and fluorogenic display. In addition to this, reversibility of $\mathrm{CN}^{-}$ interaction was endorsed up to many cycles and thus a potential reusable analytical tool for cyanide. Most importantly the PTS mechanism has also been probed in the solid-phase of the receptor, thus featuring a reusable dip-sticking approach for cyanide detection in environments outside the laboratory. The solution phase changes are strong enough to detect $\mathrm{CN}^{-}$below $10 \mu \mathrm{M}$. Thus our PTS based recognition approach has overcome the sensitivity aspects as well the tedious fabrication requirements reported in chemodosimetric approaches. To the best of our knowledge, current work represents the first example of inorganic cyanide recognition, wherein any molecular system involves an amine $\left(-\mathrm{NH}_{2}\right)$ moiety as the receptor site and displays rapid signal read-out behaviour via PTS, further realized in the solid-state too. In addition to the simple and robust solid-state dip-stick feature, the naked eye based estimation further demonstrates its potential insights.

We acknowledge IISER Bhopal for the infrastructure. We thank DST, New Delhi, for the financial support. We also thank Dr Karunesh Keshav for his help in solving the X-ray diffraction structure. Fruitful discussions with Dr Ramya Sunderraman at various stages of this work are gratefully acknowledged.

\section{Notes and references}

1 (a) K. Youngmin and F. P. Gabbai, J. Am. Chem. Soc., 2009, 131, 3363; (b) A. E. J. Broomsgrove, D. A. Addy, A. D. Paolo, I. R. Morgan, C. Bresner, V. Chislett, I. A. Fallis, A. L. Thompson, D. Vidovic and S. Aldridge, Inorg. Chem., 2010, 49, 157.

2 (a) K. W. Kulig, in Cyanide Toxicity, U.S. Department of Health and Human Services, Atlanta, GA, 1991; (b) S. I. Baskin and T. G. Brewer, in Medical Aspects of Chemical and Biological Warfare, ed. F. R. Sidell, E. T. Takafuji and D. R. Franz, TMM Publications, Washington, DC, 1997, p. 27.

3 G. C. Miller, C. A. Pritsos, Cyanide: Soc., Ind. Econ. Aspects, Proc. Symp. Annu. Meet., TMS 2001, 73.

4 D. A. Dzombak, R. S. Ghosh and G. M. Wong-Chong, Cyanide in Water and Soil: Chemistry, Risk, and Management, CRC Press, Boca Raton, 2006.

5 Y. G. Timofeyenko, J. J. Rosentreter and S. Mayo, Anal. Chem., 2007, 79, 251.

6 L. E. Santos-Fiqueora, M. E. Moraques, E. Climent, A. Aqostini, R. Martiniz-Manez and F. Sansenon, Chem. Soc. Rev., 2013, 42, 3489.
7 (a) J. Liu, Y. Liu, Q. Liu, C. Li, L. Sun and F. Li, J. Am. Chem. Soc., 2011, 133, 15276; (b) P. A. Gale, Chem. Soc. Rev., 2010, 39, 3746; (c) P. D. Beer and P. A. Gale, Angew. Chem., Int. Ed., 2001, 40, 486.

8 T. Suzuki, A. Hiolki and M. Kurahashi, Anal. Chim. Acta, 2003, 476, 159. 9 D. Shan, C. Mousty and S. Cosnier, Anal. Chem., 2004, 76, 178.

10 A. Safavi, N. Maleki and H. R. Shahbaazi, Anal. Chim. Acta, 2004, 503, 213.

11 V. K. Rao, S. R. Suresh, N. B. S. N. Rao and P. Rajaram, Bull. Electrochem., 1997, 13, 327.

12 (a) T. T. Christison and J. S. Rohrer, J. Chromatogr. A, 2007, 1155, 31; (b) J. Jo and D. Lee, J. Am. Chem. Soc., 2009, 131, 16283.

13 (a) R. M. F. Batista, S. P. G. Costa and M. M. M. Raposo, Sens. Actuators, B, 2014, 191, 791; (b) X. Cheng, R. Tang, H. Jia, J. Feng, J. Qin and Z. Li, ACS Appl. Mater. Interfaces, 2012, 4, 4387.

14 (a) P. Xiaojun, W. Yunkou, F. Jiangli, T. Maozhong and H. Keli, J. Org. Chem., 2005, 70, 10524; (b) Q. Yi, H. Jianli and T. He, Org. Lett., 2010, 12, 3320.

15 (a) S. Moloy, Y. Raghavendra, B. Bhaswati, K. K. Ravi and S. Anunay, J. Chem. Sci., 2007, 119, 91; (b) M. E. Moragues, R. Martínez Tan, Q. Zheng and P. N. Prasad, Chem. Rev., 2008, 108, 1245; (c) R. Hu, J. Feng, D. Hu, S. Wang, S. Li, Y. Li and G. Yang, Angew. Chem., Int. $E d$., 2010, 49, 4915; (d) Y. Kim, H.-S. Huh, M. H. Lee, I. L. Lenov, H. Zhao and F. P. Gabbaï, Chem. - Eur. J., 2011, 17, 2057; (e) Z. Yang, Z. Liu, Y. Chen, X. Wang, W. He and Y. Lu, Org. Biomol. Chem., 2012, 10, 5073.

16 (a) L. Yang, X. Li, J. Wang, Y. Qu and J. Hua, ACS Appl. Mater. Interfaces, 2013, 5, 1317; (b) Q. Lin, X. Liu, T.-B. Wei and Y.-M. Zhang, Chem. - Asian J., 2013, 8, 3015; (c) S. Park and H.-J. Kim, Sens. Actuators, B, 2012, 168, 376 .

17 (a) J. Ren, W. Zhu and H. Tian, Talanta, 2008, 75, 760; (b) Z. Liu, X. Wang, Z. Yang and W. He, J. Org. Chem., 2011, 76, 10286; (c) Z. Liu, X. Wang, Z. Yang and W. He, Tetrahedron Lett., 2008, 49, 6521; (d) X. Lou, L. Qiang, J. Qin and Z. Li, ACS Appl. Mater. Interfaces, 2009, 1, 2529; (e) S. Park and H.-J. Kim, Sens. Actuators, B, 2012, 161, 317; $(f)$ K.-S. Lee, H.-J. Kim, G.-H. Kim, I. Shin and J.-I. Hong, Org. Lett., 2008, 10, 49; $(g)$ C. Zhang, K. Ji, X. Wang, H. Wu and C. Liu, Chem. Commun., 2015, 51, 8173; (h) H.-T. Niu, X. Jiang, J. He and J.-P. Cheng, Tetrahedron Lett., 2008, 49, 6521; (i) X. Cheng, Y. Zhou, J. Qin and Z. Li, ACS Appl. Mater. Interfaces, 2012, 4, 2133; (j) C.-H. Lee, H.-J. Woon, J.-S. Shim and W.-D. Jang, Chem. - Eur. J., 2012, 18, 4513.

18 (a) J. H. Lee, A. R. Jeong, I.-S. Shin, H.-J. Kim and J.-I. Hong, Org. Lett., 2010, 12, 764; (b) X. Lou, L. Zhang, J. Qin and Z. Li, Chem. Commun., 2008, 5848; (c) X. Lv, J. Liu, Y. Liu, Y. Zhao, Y.-Q. Sun, P. Wang and W. Guo, Chem. Commun., 2011, 47, 12843; (d) L. Feng, Y. Wang, F. Liang, W. Liu, X. Wang and H. Diao, Sens. Actuators, B, 2012, 168, 365.

19 (a) N. Gimeno, X. Li, J. R. Durrant and R. Vilar, Chem. - Eur. J., 2008, 14, 3006; (b) A. Mouradzadegun and F. Abadast, Chem. Commun., 2014, 50, 15983; (c) E. Palomares, R. Vilar, A. Green and J. R. Durrant, Adv. Funct. Mater., 2004, 14, 111; (d) S. Vallejos, P. Estevez, F. C. Garcia, F. Serna, J. L. de la Pena and J. M. Garcia, Chem. Commun., 2010, 46, 7951; (e) F. Garcia, J. M. Garcia, B. GarciaAcosta, R. Martinez-Manez, F. Sancenon and J. Soto, Chem. Commun., 2005, 2790.

20 M. A. Kaloo and J. Sankar, Analyst, 2013, 138, 4760.

21 S.-P. Wu, T.-H. Wang and S.-R. Liu, Tetrahedron, 2010, 66, 9655.

22 (a) M. Comes, M. D. Marcos, R. Martinez-Manez, M. C. Millan, J. V. Ros-Lis, F. Sancenon, J. Soto and L. A. Villaescusa, Chem. - Eur. J., 2006, 12, 2162; (b) H. Son, G. Kang and J. H. Jung, Analyst, 2012, 137, 163.

23 (a) Y. Marcus, J. Chem. Soc., Faraday Trans., 1991, 87, 2995; (b) R. S. Dickins, D. Parker and K. I. Gloe, Macrocyclic Chemistry; Current Trends and Future Perspectives, Springer, Dordrecht, 2005, p. 121.

24 C. R. Nicoleti, V. G. Marini, L. M. Zimmermann and V. G. Machado, J. Braz. Chem. Soc., 2012, 23, 1488.

25 Y. Shiraishi, S. Sumiya and T. Harai, Chem. Commun., 2011, 47, 4953. 